\title{
Towards a Qualitative Assessment of Energy Practices: Illich and Borgmann on Energy in Society
}

\author{
Robert-Jan Geerts ${ }^{1,2}$
}

Received: 7 May 2016 / Accepted: 2 May 2017 / Published online: 16 May 2017

(C) The Author(s) 2017. This article is an open access publication

\begin{abstract}
Energy consumption is central to both a number of pressing environmental issues and to people's attempts to improve their well-being. Although typically understood as essential for people to thrive, this paper sketches a theoretical foundation for the possibility that the form and amount of energy consumption in modern society may inhibit rather than enable human flourishing. It achieves this goal by connecting and critically assessing the writings of Ivan Illich and Albert Borgmann, which offer a number of concepts that enable a qualitative discussion on energy practices. For different reasons, both authors are highly critical of the societal tendency to command ever-increasing amounts of energy. Illich focuses on negative effects of high energy consumption at the societal level, whereas in my particular re-reading of Borgmann, one finds reasons why high energy consumption fails to realize intended positive effects. It is argued that therefore, energy transition should involve a re-appreciation of the function of energy consumption: to support, rather than to be central to life.
\end{abstract}

Keywords Energy transition $\cdot$ Sustainability Energy practice $\cdot$ Illich $\cdot$ Borgmann

\section{Introduction}

Energy consumption is central to both a number of environmental issues and to people's attempts to improve their well-being. The use of fossil energy sources is leading to climate change and resource exhaustion. People travel, purchase goods, consume foodstuffs, heat their houses, and use all kinds of electric equipment in the

Robert-Jan Geerts

robertjangeerts@gmail.com; r.j.geerts@utwente.nl

1 Philosophy Group, Wageningen University, P.O. Box 8130, 6700 EW Wageningen, The Netherlands

2 Department of Philosophy, University of Twente, P.O. Box 217, 7500 AE Enschede, The Netherlands 
name of living their lives. All these activities and practices consume energy, and the received view is that if current (fossil fuel based) energy production schemes are problematic, they need to be replaced by sustainable alternatives in order to allow people to continue their consumption practices. Understanding it this way, energy transition may be mostly a technical endeavor: Society simply needs novel technologies to reliably harvest and distribute energy from a sustainable source like the sun, preferably in a form that fits current practices (electricity and liquid hydrocarbon fuels).

However, this leaves the connection between energy consumption and well-being unexamined. Is it really true that consuming increasing amounts of energy improves our lives? According to Vaclav Smil (2010, p. 724), this is not the case anymore in much of the western world: Beyond around $110 \mathrm{GJ}$ of energy consumption per person per year, there is no further improvement in relevant indicators for quality of life, such as infant mortality, life expectancy at birth, and malnourishment. Smil's conclusion is that the US average (330 GJ) indicates overconsumption and that even if it was possible to continue on this level or to grow further, the costs would most certainly outweigh the benefits. Instead, wealthy societies must learn to embrace lower energy consumption. Smil suggests that with moderate efficiency improvements, it must be possible to live decently on 80 GJ per person per year in the near future, only slightly more than the current world average (75 GJ).

The indicators Smil provides can be argued to measure a "decent" life, but not necessarily a good life. Of course, members of affluent societies want to live in good health, but that is not all there is to it: They would like to flourish, thrive, to do things that excite them, travel the world, or own a large house and a car. Do such desires explain energy expenditure beyond the decent minimum? I am not aware of hard figures on this, but I believe this is likely the case. We may call this approach to improving the quality of life the luxurious life. Is this approach successful? Research in green economics suggests otherwise. While GDP, which is closely correlated to energy consumption, steadily increased in the US over the last 60 years, the percentage of Americans considering themselves very happy with their lives did not increase (Speth 2009). Whether this is because material consumption ultimately does not lead to happiness, or because the costs (environmental degradation, harried lifestyles) outweigh the benefits, is not obvious from empirical data. ${ }^{1}$ But this situation does suggest that the relation between (energy) consumption and quality of life is more complex than is typically assumed.

Why do we consume so much energy, even when it is environmentally problematic, and it does not appear to make us happier? And what paths are available if we are to drastically reduce our consumption, whether to improve quality of life or to reach a more sustainable society? What would be good energy consumption? Mitcham and Rolston (2013) propose to call such questioning type II energy ethics, whereas type I assumes a linear relation between energy consumption and well-being, focusing only on ethical energy production methods.

\footnotetext{
${ }^{1}$ Of course, there are rationales available for this increased material consumption. Jackson (2011) suggests issues such as status anxiety (the need for consumption to signal success in life) and increasing amount of energy needed to reach the same goals (e.g., because visiting family now involves traveling further). He shows that even though all this may be the case empirically, there seems to be no explanation for why this is and whether it is the only route available. Cannot "keeping up with the Joneses" happen in terms of time spent with your loved ones?
} 
This paper contributes to type II energy ethics by discussing practices of energy consumption in modern society. In line with Borgmann (2006, p. 136), I understand practices as "regular ways of doing things," and I hold that these practices are embedded in, and largely shaped by, the environment in which they take place. Energy practices are the ways in which people expend energy: how they move around, keep warm, cook their food, produce and use objects, etc. The concept of energy practice is not contrasted to an alternative such as "nonenergy practices" but should be understood as a heuristic, a perspective to approach a myriad of human activities to explicate the energy expenditure implicit in them. Because practically any activity involves expending energy in some sense, every practice may be understood and approached as an energy practice. However, in this paper, I will focus on relatively transparent energy practices such as driving cars and heating homes to serve as examples for the general discussion.

A distinction is to be made between endosomatic (inside the body) and exosomatic (outside the body) energy expenditure. Modern technology generally enables exosomatic energy expenditure through, for example, combustion engines and electric appliances to reduce endosomatic physical labor, and indeed, one could say that industrial society is tailored towards the consumption of high amounts of exosomatic energy. A question for type II energy ethics thus becomes why the energy practices that are typical of modern life are so widespread and whether we can imagine and develop better energy practices.

The work of two thinkers is central to my approach: Ivan Illich and Albert Borgmann. Both have been critical of the effectiveness of industrial society to provide for our human needs. Energy consumption is central in Illich's critique, but his work often lacks detail. Borgmann on the other hand speaks little of energy but does provide a clear analysis of some problems of industrial society. I contribute to a broader discussion on energy transition by exploring whether and how the work of Illich and Borgmann is compatible with and complementary to each other in relation to energy practices. The resulting synthesis describes how current energy practices are problematic if one is concerned with the good life and provides guidance towards better practices.

It appears to me that neither Illich nor Borgmann has received the attention that their work warrants. Some 18 years after the publication of Illich's Tools for Conviviality, Carl Mitcham noted that "as argument, it remains young" (Mitcham 1991, p. 49) and not much has changed in the 25 years since then. Borgmann's work has been more visible within philosophy of technology, ${ }^{2}$ but his pleas for a holistic appreciation of the effects of technology on society have largely been ignored in favor of more analytic and more artifact-oriented approaches (e.g., Verbeek 2005). However, the silence around their work has not made it any less pregnant. Especially for problems like energy transition, which relate to complex systems of technologies on various scales, a broader critique of technology is more valuable than a tight focus on particular artifacts. Both Illich and Borgmann offer radical critiques to the most central ways in which modern society is organized, which lead to important insights for guidance towards good energy practices.

\footnotetext{
$\overline{{ }^{2} \text { See, for example, Higgs et al. (2000) }}$
} 


\section{Illich: Counterefficiencies of High-Energy Societies}

In the work of Ivan Illich, a narrative can be found that offers (1) an explanation for the high and increasing energy use in our society, (2) a critique of this development focused on its creation of dependence on "energy slaves" and the ultimate failure of reaching its goals, and, finally, (3) some suggestions for reform. This section sketches these three elements in succession.

Illich wrote extensively about many facets of modern society, criticizing its blind faith in narrow goals from education and healthcare to transportation. Tools for Conviviality (1973, TfC from here on) most broadly develops his theory; the short book Energy and Equity (1974, E\&E from here on) and the essay The Social Construction of Energy (2013 [1983]) deal more specifically with energy practices. In Tools for Conviviality, a critique of industrial society, Illich develops a history of tool usage. Tools are important for him because they are not neutral; they afford (Gibson 1977) or suggest certain kinds of uses over others. Not all tools can be appropriated in a way that agrees with what Illich considers a good life. Tool usage is interesting in the context of this paper because it is through tools that humanity has changed its energy practices: Any energy transition coincides with a transition of tools and a transition of thinking.

\subsection{The High-Energy Society}

If energy practices, tools, and thinking are related, which of these three is dominant? Against popular understanding, Illich holds that the steam engine was the result rather than the cause of the industrial revolution. The real revolution, that of the dominance of efficiency thinking and the emergence of "work," resulted in the appropriation of a new form of energy via fossil-fueled machinery.

The ideology of an industrial organization of tools and a capitalist organization of the economy preceded by many centuries what is usually called the Industrial Revolution. On Baconian premises Europeans began, according to Mumford, to save time, shrink space, augment power, multiply goods, overthrow organic norms and displace real organisms with mechanisms that stimulated them or vastly magnified some single function they performed. All these imperatives, which have become the groundwork of science as technology in our present society, seem axiomatic and absolute only because they remain unexamined (TfC, p. 30).

Thinking in mechanisms thus enabled humanity to replace human power with machine power, but not before humans were treated like machines first: "Up to the early nineteenth century men in English prisons actually labored on the treadmills to make machines work" (TfC, p. 31). When fossil-fueled power developed and grew more efficient, slavery and human power became uneconomical, which freed many humans from menial labor. But this was not just good news; something valuable was already lost:

The individual's autonomy is intolerably reduced by a society that defines the maximum satisfaction of the maximum number as the largest consumption of 
industrial goods. Alternate political arrangements would have the purpose of permitting all people to define the images of their own future. New politics would aim principally to exclude the design of artifacts and rules that are obstacles to the exercise of this personal freedom. Such politics would limit the scope of tools as demanded by the protection of three values: survival, justice, and self-defined work (TfC, p. 13).

Illich here criticizes the utility of economic growth by an appeal to autonomy. Whereas the current economic system obligates (or at least strongly encourages) people to participate in the "rat race," he envisions an alternative society in which people could decide for themselves how to design their lives. In order to make this happen, people must be sensitive to how their "artifacts and rules" inhibit such freedom and learn to move away from such technologies. Only then, "[a] postindustrial society must and can be so constructed that no one person's ability to express him- or herself in work will require as a condition the enforced labor or the enforced learning or the enforced consumption of another" (TfC, p. 13).

It is doubtful whether Illich's ideal situation is at all possible. As for example, Thaler and Sunstein (2008) have argued that humans are not the rational, autonomous creatures they often believe they are. Our choices and behavior are always influenced by the context, and a purely neutral context is simply not possible. Choices are always presented in a specific order and often include a default option. In many cases, such as when designing the infrastructure of a new area to be developed, only one layout of options (roads and paths) can be implemented. How can this be squared with the aim of "permitting all people to define the images of their own future"? It is impossible to principally exclude all artifacts and rules that obstruct personal freedom, as Illich would like. This is not to say that it cannot be a worthy ideal to aspire to, but we must be aware of its utopian character.

A postindustrial revolution as envisioned by Illich would entail a significant energy transition. Illich suggests that it would radically reduce energy consumption, because "[p]eople will rediscover the value of joyful sobriety and liberating austerity only if they relearn to depend on each other rather than on energy slaves" (TfC, p. 14).

The structure of the problem according to Illich is thus as follows: Industrial society is based on mechanistic thinking, which has not only expanded affluence via exosomatic energy usage but also reduced autonomy. If we are to regain autonomy, we must go beyond the mechanistic thinking of the industrial society, and this would lead to letting go of our energy slaves. The new energy regime must come out of a new understanding of life and society, and therefore, we cannot design a new energy system before we are thinking in the way that this new energy system is to be built on. A "modest" transition from fossil to renewable sources will perpetuate all our societal ills as long as we simply aim to replace electricity from coal and gas to electricity from solar and wind, as this does not address the underlying problem. In order to defend this claim, it is necessary to explore why dependence on energy slaves is so problematic for Illich.

\subsection{Energy Slaves and the Good Society}

How exactly does an industrial society reduce the autonomy of its inhabitants? Illich goes into more detail in Energy and Equity (1974), a short book on the problems of 
motorized traffic, which can be understood as an example of energy practices in general. He here distinguishes between transit (self-powered, autonomous travel) and transport (motorized carriage of passengers). As soon as transport starts dominating traffic, it creates a number of problems.

As soon as people become tributaries of transport ... the contradictions between social justice and motorized power, between effective movement and higher speed, between personal freedom and engineered routing, become poignantly clear. Enforced dependence on auto-mobile machines then denies a community of self-propelled people just those values supposedly procured by improved transportation (E\&E, pp. 15-16).

One problem is that of equality. When speeds increase, it turns out that the cost of the speediest transportation is carried by the people who cannot afford its use. The elite that benefits from it, bypassing city traffic on elevated highways, or traffic jams in jet airplanes, does so at the cost of the rest of society, which spends more time getting from A to $\mathrm{B}$ because the highway blocks the direct route, pays more taxes to build the infrastructure, and finds the built environment expanding because of all the space demanded by vehicles.

But even if a society manages to circumvent this inequality by organizing speedy transportation for all, by offering a well-organized and classless public transport system, it still runs into trouble: "High speeds for all mean that everybody has less time for himself as the whole society spends a growing slice of its time budget on moving people. Vehicles running over the critical speed not only tend to impose inequality, they also inevitably establish a self-serving industry that hides an inefficient system of locomotion under apparent technological sophistication" (E\&E, p. 37).

Illich gives the example of the time the average American in his time spent on their car: $1600 \mathrm{~h}$ a year. "He sits in it while it goes and while it stands idling. He parks it and searches for it. He earns the money to put down on it and to meet the monthly installments. He works to pay for gasoline, tolls, insurance, taxes, and tickets" (E\&E, p. 18). With an average mileage of 7500, this translates into an average speed of 5 miles an hour. "In countries deprived of a transportation industry, people manage to do the same, walking wherever they want to go, and they allocate only 3 to 8 per cent of their society's time budget to traffic instead of 28 per cent. What distinguishes the traffic in rich countries from the traffic in poor countries is not more mileage per hour of life-time for the majority, but more hours of compulsory consumption of high doses of energy, packaged and unequally distributed by the transportation industry" (E\&E, p. 19). JeanPierre Dupuy repeated this exercise in France and found a similar result (Dupuy 2002).

Transportation develops into what Illich calls a radical monopoly, which is not the monopoly of a specific automobile producer, or even the monopoly of automobiles over trains, but of transport over transit. It is called radical because of its "hidden, entrenched, and structuring nature" (E\&E, p. 45), successful "by virtue of its acquired ability to create and shape the needs which it alone can satisfy" (E\&E, p. 47).

So not the specific organization of transport (public or privately owned; automobiles or trains; increased efficiency or just increased power) is the problem, but the very idea of speedy transportation. Beyond roughly the speed of the bicycle, there are only disutilities: We spend more time and physical resources on travel, change our 
environment in a way that discourages transit, feel disheartened while being stuck in traffic jams, and increase inequality.

Transportation stands model for industry in general. Illich formulates the general case as follows: "Any industrial product that comes in per capita quanta beyond a given intensity exercises a radical monopoly over the satisfaction of a need" (E\&E, p. 46). Wherever industry colonizes a practice, it creates counterintuitive inefficiencies. Illich also mentions education (which allegedly destroys an environment fit for learning) and medicine (which creates new illness). To remain on the topic of energy, one can think of examples like air conditioning, which heats city streets, creating urban "heat islands" in already warm regions, and industrial agriculture, which demands higher caloric inputs (by means of power tools, artificial fertilizers, and transportation) than their food output.

In its most general form, Illich holds that the problem of industry is overefficiency. Overefficiency, or the counterproductivity of narrow goals, refers to the problem that sustained efforts towards a certain goal will at some point actually undermine it. Illich describes the development of this effect via two "watersheds." The first watershed refers to the moment that a technological system represents a net gain compared to the traditional method: The moment that going to a doctor instead of just waiting increased your chance of getting better, or the moment mechanized transport became faster than walking. The second watershed refers to the moment at which further development of the system does more harm than good: when a medical treatment is more likely than not to create new (iatrogenic) diseases or when faster vehicles or bigger roads lead to more rather than less time spent traveling (or working to fund traffic). Given enough time, every technological system will pass both watersheds. The good society is to recognize these watersheds and inhibit development past the second.

\subsection{A Program for Transformation}

In both Tools for Conviviality and Energy and Equity, Illich provides ideas for a better society. The task is threefold: "First, the need for limits on the per capita use of energy must be theoretically recognized as a social imperative. Then, the range must be located wherein the critical magnitude might be found. Finally, each community has to identify the levels of inequity, harrying, and operant conditioning that its members are willing to accept in exchange for the satisfaction that comes of idolizing powerful devices and joining in rituals directed by the professionals who control their operation" (E\&E, pp. 10-11).

Although that third task is described rather cynically, it should be noted that Illich does not completely reject those tools that would, if left unchecked, lead to radical monopoly. The important thing is that these technologies are accepted for what they are and carefully monitored in order to guard society against falling into their trap. With this having been said, we can take a closer look at the positive program behind the critique.

Good tools, for Illich, are convivial, literally those tools that "live together" with their users. "Tools foster conviviality to the extent to which they can be easily used, by anybody, as often or as seldom as desired, for the accomplishment of a purpose chosen by the user. The use of such tools by one person does not restrain another from using them equally. They do not require previous certification of the user. Their existence 
does not impose any obligation to use them. They allow the user to express his meaning in action" (TfC, p. 22).

Once again, one should notice that these goals are probably not completely achievable in each and every case because of the inescapability of choice contexts and default options. Although any strict "obligation" may be prevented, tools will always suggest a certain use or inspire one kind of behavior rather than another. Illich seems to argue that convivial tools are strictly instrumental in their use and that their availability does not change people's actions and desires at all. Although possibly strive worthy, this ideal is impossible to achieve.

Illich believed that "[ $\mathrm{t}$ ]ools for a convivial and yet efficient society could not have been designed at an earlier stage of history. We can now design the machinery for eliminating slavery without enslaving man to the machine. Science and technology are not bound to the peculiar notion, seemingly characteristic of the last 150 years of their application to production, that new knowledge of nature's laws has to be locked into increasingly more specialized and highly capitalized preparation of men to use them." (TfC, p. 33) Unfortunately, Illich does not give any concrete details about an "alternative" science and technology. ${ }^{3}$

Although Illich holds that life in a reformed society will be objectively better, he is not confident that this knowledge is enough to initiate the transformation.

To invert politics, it will not be enough to show that a convivial life style is possible, or even to demonstrate that it is more attractive than life in a society ruled by industrial productivity. We cannot rest with the claim that this inversion would bring society closer to meeting the goals now stated as those of our major institutions. It is not even enough to show that a just or socially equal order can become a reality only through a convivial reconstruction of tools and the consequent redefinition of ownership and power. We need a way to recognize that the inversion of present political purpose is necessary for the survival of all people (TfC, pp. 43-44).

Here, a problem emerges. In some cases, "the survival of all people" and better life of those people coincides, but in other cases they do not. "The barriers beyond which destruction looms are of a different nature from the boundaries within which a society freely constrains its tools. The former establish the realm of possible survival; the latter determine the shape of a culturally preferred environment" (TfC, p. 78). The culturally preferred environment will always be a subset of the realm of the possible: If it is not possible, a certain situation will not be preferable either (so there are no preferable nonpossible situations), but we can imagine possible non-preferable situations. If the transformation can only take place by an appeal to the possible (i.e., a situation in which the survival of all people is not threatened), this will not help with making sure that the situation will also end up being preferable.

The seriousness of this problem becomes clear when Illich states that "[e]ven clean and equally distributed electricity could lead to intolerable radical monopoly of power tools over man's personal energy" (TfC, pp. 76-77) or “[e]ven if planes and buses

\footnotetext{
${ }^{3}$ Arguments can be made that, e.g., open source software, modern organic and permaculture farming, and offgrid passive solar houses could fit the bill.
} 
could run as nonpolluting, nondepleting public services, their inhuman velocities would degrade man's innate mobility and force him to spend more time for the sake of travel" (TfC, p. 52). Many current efforts towards a sustainable energy system (efficiency improvements, sustainable sources) are aimed at developing exactly the kind of energy system that Illich argues to be part of the possible non-preferable. It is therefore not clear whether his project is really helped by the recognition that we need a change "for the survival of all people."

Nevertheless, Illich's description of the preferable situation adds a valuable dimension to our understanding of excessive energy consumption. He argues that it is not merely a zero-sum game of the positional good of having more energy at your disposal than others but in fact a negative-sum game in which the whole of society loses due to the effects of radical monopoly and overefficiency. High energy consumption is misconceived because it does not lead to its perceived benefits, and it locks society further into the "mechanistic" thinking on which high energy consumption is based. This increases the difficulty of moving towards a more "convivial" set of tools that would lead to different energy practices based on autonomy and equity.

Illich himself was already aware that this knowledge alone is unlikely to bring about positive change, but the "ally" he proposed is problematic because of its alternative boundaries. In the next section, I turn to Albert Borgmann, because his work offers a positive complement to Illich that may align better with Illich's ideas of the good society than his own move towards concerns of survival.

\section{Borgmann: the Device Paradigm and Commodification of Consumption}

Writing a decade after Illich, Albert Borgmann explores many of the same topics in Technology and the Character of Contemporary Life (1987, TCCL from here on). A close look at his argument will allow me to critically relate to Illich's argument and build a new perspective on energy transition upon their shared foundations.

For Borgmann, the defining characteristic of modern technology is its tendency to commodify things of value: making them available instantly, while hiding the machinery that brings forth these commodities. ${ }^{4}$ The resulting structure of technological societies he calls the device paradigm. A common example in his work is a typical energy practice: the way we heat our homes. Whereas people used to have a central fireplace which needed maintenance and the chopping of wood before winter, modern houses are heated by central heating systems, often tucked away in a closet and fed by an underground natural gas pipeline. A thermostat allows the inhabitants to easily adjust the heat and in many cases to program the system so that it is already heated up by the time they return from work. So far so good, as there seems to be little to object to getting rid of chores. The problem for Borgmann is that the fireplace used to be more than a source of heat. A fireplace was a focus, the center of the house, a place where the family gathered to interact with each other. Chopping wood was not just a way to make

\footnotetext{
${ }^{4}$ Borgmann's notion of commodity is related but not identical to the concept of commodity in economics. They may be produced in the same manner and even refer to the same object, but whereas the latter field understands a commodity in terms of its tradability and exchangeability, for Borgmann, the key is its "consumable availability" that leads to disengagement and distraction for the consumer (TCCL, p. 259)
} 
sure one did not freeze to death in the winter; it connected people with their surroundings, so they learned to appreciate the gifts of nature. By commodifying heat, these engaging practices were lost and a one-dimensional consumption remained. Disengaging technologies like a central heating system are called devices, as opposed to traditional things. ${ }^{5}$ "Commodities, in comparison with focal things, are highly reduced entities and abstract in the sense that within the overall framework of technology they are free of local and historical ties" (TCCL, p. 81). The device paradigm leads people to focus more and more on the consumption of commodities, while engagement with one's surroundings becomes increasingly difficult.

Verbeek (2005) argues that this is a single-sided view of the effects of technologies on our lives: A technology like the telephone can connect people with distant friends and relatives, something impossible without telecommunication. Describing technologies in terms of the device paradigm appears to focus only on impoverishing effects of technology, ignoring the enriching ones. Borgmann agrees that engaging technologies exist, but his point is that disengaging technologies seem to be much more ubiquitous than engaging ones (Borgmann 2002).

At one point, Borgmann calls engaging technologies instruments (TCCL, p. 221). These are tools that enable people to engage in focal practices, activities that are valuable in themselves and that revolve around focal things. The peculiar position of instruments is further explained in an endnote: "[a]lthough these technological instruments are translucent relative to the world and so permit engagement with the world, they still possess an opaque machinery that mediates engagement but is not itself experienced either directly or through social mediation" (TCCL, p. 289 n. 23). Examples of instruments are running shoes and freeze-dried food which enable one to explore trails in the wilderness, musical instruments that allow friends to make music together, or kitchen appliances that help people prepare their own meals. People do not engage with instruments, but through them, the engagement with the focal things (the trail, the musical piece, or the shared meal) is mediated by instruments. ${ }^{6}$ When Verbeek argues that the telephone can be used to connect with distant friends, he argues that it can be used as an instrument.

Devices and instruments are the objects through which practices become energy practices: A conversation with a loved one becomes an energy practice when a system of cellphones, transmission towers, and data centers is powered to facilitate it. The same system can of course also be used to consume the commodity of mass media (and

\footnotetext{
${ }^{5}$ The word "thing" is used in two distinct ways in the work of Borgmann. First, there is the (pre-modern) thing as opposed to the device, a technological object that can be used in a number of ways, and not necessarily in the context of a focal practice (e.g., a hammer). Second, there is the "focal thing," the object towards which focal practices are aimed. These can be either natural (wilderness) or human-made (a musical piece) and physical (a mountain) or psychological (a shared meal).

6 These examples are only "instruments" for Borgmann to the extent that they also "possess an opaque machinery." A violin is not an instrument in this sense, but rather a focal thing - the player is able to understand its functioning through resonating materials. A synthesizer on the other hand is opaque: The player has no insight into the process that results in the creation of sounds. Similarly, the runner does not understand the molecular behavior of the rubber compound used for the soles nor does the cook understand the source of the electricity that powers a food processor. More may be said about this, but the distinction between (fully transparent) focal things and (partly opaque) instruments is somewhat tangential to the aim of this paper. The crux is the distinction between (disengaging) devices on the one hand and (engaging) instruments and focal things on the other. For an extended discussion on focal things in the work of Borgmann, see Haworth (2000).
} 
thus function as a device). A better understanding of this difference enables a more nuanced appreciation of the ways in which energy consumption may be beneficial to individuals, as we shall see in Sect. 5.

Although Borgmann does not explore this, there is no sharp divide between instruments and devices, as technologies can be used for different purposes. Even the dreaded television, the cause of the "couch potato" can be used in an engaging manner, for example, when one watches a debate program which ignites a discussion with other viewers of the program. On the other side, running shoes can be used to run on a treadmill for the sole purpose of staying fit, a practice that commodifies health. But treadmills too can be used in focal practices, for example, when they facilitate meaningful connections with companions in the gym.

The point is not to strictly divide the world into devices and instruments but to understand that there are different ways of using technologies. Counterexamples do not diminish the potency of Borgmann's insight. Different technologies do afford or inspire different uses and will encourage one practice over another. Furthermore, we should notice that indeed, contemporary society seems to be built mostly around devices rather than things and instruments. And this is where Borgmann focuses his critique on modern society: Members of it tend to develop practices that are not contributing to an engaged life. Because Borgmann holds that commodities are ultimately empty, he argues that instead of comfortable, attention-scattering commodious consumption, we should partake in focal practices. ${ }^{7}$

Borgmann describes practices as regular ways of doing things (Borgmann 2006, p. 136). They form and evolve over time, influenced by our environment, values, and dedication. Focal are those practices that give direction and meaning in one's life, that are "centering and orienting" (TCCL, p. 207). Borgmann describes them starting from focal practices in "mythic times," when a "divine power or mythic ancestor" was founded and consecrated. "A sacred practice, then, consisted in the regular reenactment of the founding act, and so it renewed and sustained the order of the world" (TCCL, p. 207). Part of the force of such practices came from their opposition; the alternative of the order defined by the myth was chaos and disorder. Modern focal practices do not benefit from such direct opposition, but they do benefit from a deeper, more subtle one. Technology, understood as the device paradigm, must be understood as a practice as well, but importantly not a focal one. It has not arisen out of a founding event that had a focal character, and it has "a debilitating tendency to scatter our attention and to clutter our surroundings" (TCCL, p. 208). Once one has appreciated this tendency and has realized the "pervasiveness and consistency of its pattern" (TCCL, p. 208), one comes to understand that it "must be countered by an equally patterned and social commitment, i.e., by a practice" (TCCL, p. 208). That is to say, a few "focal things" here and there dispersed in our lives are not enough to break the pattern. We need to arrange our lives in ways that are structurally centering and orienting. Only through such an enduring commitment can the device paradigm be broken, because structural commitment would displace the consumptive activity that is characteristic of the device paradigm.

Like Illich, Borgmann hopes that this insight will have a transformative effect. People should be made aware of the device paradigm, so they can develop a critical

\footnotetext{
${ }^{7}$ Although Borgmann denies the positive enrichment role of devices, he does argue for the positive value of devices in a "supporting role" to focal things and practices. I return to this point in Sect. 5 of this paper.
} 
stance towards devices. This awareness would lead to a (better) balance between the use of instruments on one hand and devices on the other. Discussions about such topics can only occur as "deictic discourse" according to Borgmann: appeals to certain understandings of the world as participant, rooted in specificities of one's life. ${ }^{8}$

How such a discussion can take shape in the context of energy practices will be explored in Sect. 5 of this paper, but first, I will have a closer look at the connections between the work of Illich and Borgmann, because although they write about similar issues, they use different vocabularies. In the next section, I will show that these vocabularies appear to be strongly complementary, resulting in a broad basis to develop a critique on modern energy practices.

\section{Synthesizing Illich and Borgmann-Connecting Vocabularies of Critique}

Borgmann is critical of the work Illich and mentions that "we may lead the disengaged and distracted life that is typical of advanced technology in the midst of conviviality as defined by Illich" (TCCL, p. 167). This hints at a key difference between the two thinkers. Illich is looking at negative design rules: those guidelines that inhibit practices obstructing people's abilities to live good lives. Borgmann finds a more positive approach and focuses on what people need to actually live the good life. This is a narrower solution space, but one that is likely to overlap to a very large extent with the one that Illich envisions, hence Borgmann's qualification that conviviality "seems like a reasonable demand" (TCCL, p. 167). If we are interested in the good life as Borgmann envisions it, Illich's work is valuable to recognize a broad variety of practices in industrial society that demand reform, so that we are already moving in on a situation that Borgmann could accept.

Beyond these dissimilar starting points, powerful connections in terminology can be found between the two thinkers. Here, I discuss a number of such connections between Borgmann's concepts of instruments, devices, and the device paradigm and Illich's concepts of overefficiency, watersheds, conviviality, and radical monopoly, as well as their respective positions on the level of technology and worldviews.

Borgmann's concept of commodification is a practice that can only occur in a society that values efficiency: A commodity is successful exactly because it appears to deliver a good in a more efficient way than was otherwise possible. Do devices also tend to overefficiency? This seems not the case in the most obvious sense. A central heating system does not, in the end, fail to deliver warmth. But in a broader understanding of its function, when we appreciate what other functions a hearth fulfilled, it

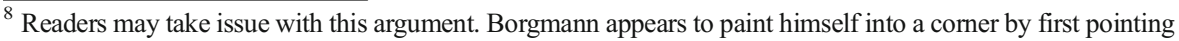
at the moral significance of our (technological) surroundings and then arguing that the only way to discuss these things is to write from our own experience. This appears to allow an accusation of moralizing, in the negative sense of the word: baseless judging of actions in terms of right and wrong. If we can only use our own experience and nothing more objective, how can we possibly make claims about behavior beyond stating that it is up to us as individuals? Without sketching a full defense of his position here, I remark that he may simply be right that (1) our environment is morally relevant (cf. Verbeek 2011) and that (2) morality is ultimately based in personal experience, and general rules are only general because we happen to share them across a society (and beyond). Analogous to my intentions in this paper, Borgmann does not tell anybody what to do, except to reflect upon and discuss their practices and habits.
} 
seems that the efficiency of the central heating system is a false one: By optimizing heat throughout the house, it has actually, according to Borgmann, reduced the quality of life within it. And was not the aim of the central heating system to create a home that was better to live in? If so, a central heating system is overefficient: By narrowly optimizing the provision of heat, we may end up losing more than we gain. Because devices work exactly by narrowing and one-dimensionally re-interpreting the functioning of instruments, they tend towards overefficiency. Borgmann's theory of the device paradigm can thus be used to extend and refine Illich's concerns with overefficiency: It allows for a broader application of the term in cases where the functions of a tool cannot be reduced to a single dimension. Although a central heating system does not leave us cold like "fast" transportation slows us down, it still is a form of overoptimization of the narrow goal of heating to the detriment of the auxiliary functions of its predecessor, the hearth. ${ }^{9}$

The idea that devices tend towards overefficiency suggests that we should talk about instruments and devices in terms of two watersheds. I already argued that the line between instruments and devices is not always clear-cut - technologies may be used in different ways. Assuming that the good life revolves around focal activities, a specific technology will pass the first watershed and function as an instrument when it enables one to (better) indulge in such an activity, and it passes the second and becomes a device when it becomes countereffective. For example, the bicycle passes the first watershed when it allows one to appreciate the landscape better than while walkingperhaps because it increases the radius that one can explore within a day. It is an instrument that enables one to partake in the focal practice of exploring one's environment. But when the technology develops, when skinnier tires inhibit exploration of gravel roads, or the more aerodynamic pose becomes uncomfortable after an hour or two, it passes the second watershed and starts inhibiting the focal aims of the ride in exchange for "performance": It becomes a device for a "workout" or swift transportation. However, further development of the bicycle can also go in other directions, for example, by adding suspension and extra low gears, enabling the cyclist to ride single tracks as well as regular roads, leading to a whole new experience of a mountain. Both when designing technologies and when choosing which ones to use in our daily lives, the concept of the two watersheds is helpful in guiding our assessment of a particular tool: In which ways does this help the user with what? Will it allow one to do one thing very efficiently, or does it help the user with certain focal practices?

The example of different bicycles also suggests that the level of technology is not necessarily related to its usability as instrument or device. This leads back to Illich's remark that the level of technology is not related to its conviviality. Neither Borgmann nor Illich can be accused of being traditionalist or Luddite when it comes to their preference for what seem to be "old" technologies, but perhaps they can be considered conservative when it comes to their understanding of quality of life. Their tendency towards older technologies results from the fact that many more recent technological

\footnotetext{
${ }^{9}$ A problem with Illich's overefficiency argument is the subjectivity of time accounting. There is no objective way to decide exactly which activities are part of the means towards a specific goal and which are not. Is, for example, the price people are willing to pay for a certain style of car over a car with the same functionality part of the costs for automobile traffic? This problem is amplified in the case of Borgmann's broader understanding of the functions of devices and instruments - depending on one's intentions, it would be easy to manipulate the calculus.
} 
developments have been used to come up with (over)efficient rather than convivial tools and devices rather than instruments. But this is not necessary. Ultralight hiking gear for example is high-tech, yet clearly instrumental to the focal activity of spending time in the outdoors. Online communities can be very convivial.

This apparent symmetry makes one wonder whether instruments are always convivial. Let us recall Illich's guidelines for convivial tools: “Almost anybody can learn to use them, and for his own purpose. They use cheap materials. People can take them or leave them as they wish. They are not easily controlled by third parties" (TfC, p. 64). Instruments can be difficult to master (e.g., an analog synthesizer) and may use expensive materials, but they seem to allow (or even encourage) people to use them for their own purpose. Convivial tools are not always instruments. If they are used in focal activities and function transparently, Borgmann would categorize them as focal things. If they are used for other than focal activities, they would be mere things: The hammer ticks all the boxes for conviviality but is a thing rather than an instrument. Here, we once more find a key difference between the two thinkers that is closely related to the difference between a positive and negative approach mentioned above: Borgmann is not interested in those activities that are needed for survival but have little to do with focal activities. Convivial tools may be used for such purposes, but they may also be used for focal activities. Instruments are therefore a subset of convivial tools. Devices are never convivial: They are tailored to produce a specific commodity and can therefore not be used "for one's own purpose." In the device paradigm, it is awfully hard to "take them or leave them as one wishes."

This final remark suggests that the device paradigm, the situation in which individuals are surrounded with devices and life revolves around the consumption of commodities, is the situation in which devices enjoy a radical monopoly over things and instruments: Devices have created needs (of speedy transportation, material opulence, etc.) that only they can fulfill.

A more complex parallel can be found with regards to worldviews. Borgmann argues that next to the allegedly wrong use of the time saved, the very notion that time is saved when not having to spend it on all kinds of chores anymore is only possible from the perspective of the device paradigm, because within this perspective, labor is seen as "mere means." The thorough separation of means and ends makes us "exaggerate the liberating character of the transformation of work and thus cover up the concomitant cultural and social losses" (TCCL, p. 119). Borgmann thus claims that in a pretechnological society, people did not see cutting wood as a mere means to stay warm in winter but as an integral part of their lives. Another factor contributing to our disdain for labor such as cutting wood is tied to the fact we understand it as "unskilled": The tools used are not as complex as modern devices, and our lengthy education is not aimed at such manual work. Implicitly, we assume that complex devices are more difficult to operate than simple things, even though devices tend to not require much skill from their users, while a thing like an axe demands a certain amount of dexterity and know-how to use it.

Both these points can also be found in the work of Illich: Radical monopoly of education pushes away traditional practices that become "chores"; in The social construction of energy, he mentions that the pilgrim and the modern traveler do not traverse the same world. Motorized transport transforms space: "By transforming commons into resources for the production of passenger miles, vehicles take the use 
value out of feet" (Illich 2013, p. 120). By transforming the very nature of the issue at hand, quantitative comparison becomes impossible. The perception of gains and losses is worldview related.

The key task is to become aware of this worldview and develop a critical stance towards it. Borgmann states: "As long as we overlook the tightly patterned character of technology and believe that we live in a world of endlessly open and rich opportunities, as long as we ignore the definite ways in which we are, acting technologically, have worked out the promise of technology and remain vaguely enthralled by that promise, so long simple things and practices will seem burdensome, confining, and drab. But if we recognize the central vacuity of advanced technology, that emptiness can become the opening for focal things" (TCCL, p. 199).

This is to break through radical monopoly.

\section{A Renewed Look at Energy Transition}

With this combined critique of industrial consumption in mind, the aims of the energy transition now become bigger than ever. If exosomatic energy consumption is central to the industrial way of life, and this can only be countered by "an equally patterned and social commitment"; then, a radical re-appreciation of energy consumption is necessary. But in order to defend such large claims, I will carefully develop my argument.

Even though Borgmann seems to hold a position that is largely compatible with Illich's energy-critical approach, he does not explicitly mention energy consumption himself. What, if there is any, is the problem for exosomatic energy use for Borgmann? Are focal practices always (or likely to be) low energy? Borgmann provides us with a useful clue to build on:

Running is simply to move through time and space, step-by-step. But there is splendor in that simplicity. In a car we move of course much faster, farther, and more comfortably. But we are not moving on our own power and in our own right. We cash in prior labor for present motion. What I am doing now, driving, requires no effort, and little or no skill or discipline. I am a divided person; my achievement lies in the past, my enjoyment in the present. But in the runner, effort and joy are one; the split between means and ends, labor and leisure is healed (TCCL, p. 202).

Borgmann here argues that the split between production and consumption is the key reason why driving automobiles does not fit the centered life: By first having done the work and later appreciating its benefits, one is not "focused" in the present activity. This, I hold, is problematic. I claim that the internal combustion engine and its commodified power are more central to the issue Borgmann tries to get at than the temporal split between means and ends. Consider, next to the runner and the motorist, a cyclist who, after sweating up a mountain pass, enjoys a high-speed descent on the other side. Their high speed is not a direct result from their own power, but rather an indirect one: The cyclist has gained potential energy on the way up and is now cashing this in with gravity's downward pull. There is a clear temporal division between mean and end, but still, there is an undeniable engagement and focus in the activity. The 
practice is much closer to that of the runner than that of the motorist, because of, I would argue, the bodily source of the effort.

But does this argument hold up closer scrutiny? Going a little further, we may imagine a stationary bicycle used to charge batteries for an electric car, which, after a week of relentless pedaling, is taken out for a drive. Does this result in an exhilaration similar to the descent from the mountain pass? Probably not, even though the original energy source is the same. Perhaps the example of the bike ride is misleading because of poor demarcation. Without the way up, the descent becomes meaningless: It is because we directly worked our way up, that we can enjoy the way down. The bike ride should therefore be approached in its whole, and when ascent and descent become one, means and ends do too.

But this raises further questions. If we can combine different parts of a bike ride, why would we not say that the year of work in a cubicle and the 2-week holiday that it pays for are both part of the whole of the practice of "modern life"? Is this at most a difference of degree, rather than of kind? No. The key here, I believe, is that there is a clear symmetry or reciprocity between the two parts of the bike ride, where there is none in the case of a year's work paying for a holiday.

As long as we are embodied beings, any focal activity will revolve around bodily engagement, and therefore bodily energy expenditure. Exosomatic energy use to fuel an activity intrinsically leads to an asymmetry between (exosomatic) means and (endosomatic) ends. Like the telephone, as Borgmann himself argues, such technologies may "support, but could not be at the center of, a life worth living" (Borgmann 2000, p. 352). Rather than temporality, the asymmetry between means and ends should be understood as the key difference between running and driving for Borgmann.

This does not condemn exosomatic energy use in general, but it significantly narrows its appropriate application. It suggests that any attempt to make focal activities easier with power tools, be it kitchen robots to prepare meals quicker or airplanes to travel faster, are bound to fail reaching their goal. The well-lived life according to Borgmann avoids many modern technologies not because of an alleged romanticism but because of the anthropological position that we are embodied beings.

But this is likely to ring all kinds of bells with the field of philosophical anthropology. Were we not, according to, e.g., Gehlen (1980) and Plessner (1975), the animal that needed technology to be in the world? Do we not, with Latour (1993), become part of all kinds of networks, without which we would not be fully human? This may be the case, but using this to argue for exosomatic energy use will only defend its supporting function, and this is not under debate. We may use exosomatic energy to sustain life, perhaps even to support us in our focal practices (e.g., to drive a car to a trailhead to start hiking). But focal practices themselves do not at all benefit from exosomatic energy use, because it is incompatible with endosomatic experience. Technology may mediate our experience in the world (Ihde 1990), but the experience itself still occurs in our bodies (at least until we become transhumans).

We must be careful however not to equate focal activities with bodily experience. Endosomatic energy consumption may be necessary, but it is not sufficient for a practice to be focal. Running on a treadmill, for example, is but a weak, commodified version of running in the wilderness or through town. Although the running still happens with our own body, the practice is taken out of its context, the disclosure of one's environment in all its richness. One may still be able to cultivate a healthy body 
or experience a runner's high, but one cannot engage with a technical trail, the wind and the sun, the fresh air, and chance encounters anymore. Borgmann's good life revolves around low-energy practices, but not all low-energy practices lead to good lives.

One issue remains: What about the hearth, Borgmann's paradigmatic focal thing, burning wood, and centering lives? The hearth clearly functions via exosomatic energy; it creates an environment that allows our bodies to keep their temperature steady in cold climates. It has allowed humanity to spread over the earth. It seems to me that although the hearth works very well as an example to explain the centering effects of focal things, its warming function is not central to its functioning as a focus. In its design of supporting life, the hearth simply happened to gather the members of the family, who then proceeded to have a centered life. In warmer climates, where heat is not in demand, the shade under a big tree may have a similar function, or people still congregate around the fire where the food is being made. The hearth (or the fire in the kitchen) feeds the body with food and sometimes warmth and feeds the soul with company. It is not a tool to do exosomatically what used to be done endosomatically, but a source that feeds us in multiple ways.

\section{Conclusion}

Taken together, Borgmann and Illich suggest that an ever-increasing access to exosomatic energy does not improve our lives, and in some ways deteriorates it. Building on statistical evidence, this has been argued before by, e.g., Vaclav Smil $(2007,2010)$. The idea that (exosomatic) energy consumption has little to do with wellbeing goes against traditional understandings of progress, and indeed economic policy in most countries. However, it does square with findings in positive psychology and arguments made in favor of an energy ethics that discusses the appropriate level of energy consumption, rather than only a debate on which sources are best (Mitcham and Rolston 2013).

Both Illich and Borgmann provide us with a number of plausible theoretical explanations of why this is the case. Borgmann explains why it is impossible for exosomatic energy consumption to directly improve our quality of life. Energy transition should therefore involve a re-appreciation of the function of energy consumption: to support, rather than to be central to life. This support should not get in the way of focal practices, and Illich has shown how easy it is for industrial society to get bogged down, become counterproductive, and consume more and more time and resources without delivering anything valuable at all.

This knowledge can help society envision the route to better low-energy lives. As we have seen, it is not simply a limit on the amount of energy per capita, as, for example, the 2000W society (Hänggi 2011) would have it, but rather a qualitatively different approach to energy consumption that makes for good living. Understanding what kind of energy consumption may or may not actually improve well-being enables both individuals to make informed choices when designing their lives, and societies to put in place prerequisites to make low-energy choices, such as an infrastructure tailored towards transit rather than transport or a level playing field for local food production. These insights on the specifics of energy consumption may help to further refine other efforts aimed at theorizing alternative consumption practices, such as voluntary 
simplicity (Gambrel and Cafaro 2009), alternative hedonism (Soper 2008), and NeoEpicureanism (Spence 2012).

Reflection and discussion on energy consumption are promoted in this paper in two ways. First and foremost, Borgmann offers a vocabulary in which it becomes possible to see nuanced differences in energy practices. To make people more conscious of the differences between commodified entertainment and focal activities is the first stage for them to act on these matters. Awareness may lead more people to lead a rich, lowenergy lifestyle simply because it makes them realize they prefer it. Next to this possibility for individuals, it enables a political sensitivity to the ubiquity of devices in society. Individual agency is limited because all our choices are partly preordained by the context in which they take place. A society aware of the problems of devices can choose to change this context in order to make it possible for people to choose differently.

Second and more contentiously, Borgmann starts a debate simply by taking a position. With his plea for focal practices, he makes a first move in a discussion that typically does not happen at all in our liberal society: The good life is usually understood as something for everyone personally to figure out. However, a qualitative discussion concerning this is valuable for a number of reasons. Firstly, because in its structure our society is far from neutral on the matter, and secondly, at least when one does not hold the position that well-being is completely subjective, people probably benefit from reflecting on their own practices in order to improve them.

Borgmann argues against what he calls commodious individualism: "the unencumbered enjoyment of consumption goods or commodities" (Borgmann 1992, p. 43). In the context of this paper, I believe that those who object to Borgmann's position on the good life because they prefer the life of the commodious individual face at least three challenges. First, there is the question whether or not their preferences are caused by the pattern of modern technology and the logic of the growth economy. How do people become commodious individuals? It seems to me that at least some of them may have been lured into appreciating this lifestyle through ceaseless marketing and the decreasing possibility to choose otherwise. Illich suggests that this is exactly what is happening when he speaks of industry creating and shaping needs that only it can satisfy (E\&E, p. 47). If this is the case, then there is no reason to continue in this direction other than the fact that we are already on our way.

Second, Illich makes a strong case around the counterproductivity of optimizing narrow goals. To what extent do commodious individualists manage to avoid this trap? If their big cars and comfortable suburban dwellings demand working longer hours and spending more time in traffic jams, they may be simply fooling themselves. It may be that different choices (e.g., living in slightly smaller houses with shorter commutes) would lead to better lives as conceived by commodious individuals themselves.

Finally, adherents to commodious individualism need to come to terms with the environmental consequences of their behavior. If it is true that excessive consumption of all sorts of resources leads to ecological degradation, climate change, etc., and that commodious individualism embraces patterns of ever-increasing consumption, how do they plan to balance the good with the bad? This is a complicated problem in the short term but becomes steadily more complicated as continuous growth increases pressures on many fronts. Are mechanisms of restraint possible when they would suggest behavior exactly opposite of one's understanding on how to improve well-being? 
Combined, these three challenges should be enough to give the reader pause and consider the alternative sketched here on the basis of the writings of Illich and Borgmann.

Acknowledgements Thanks to Albert Borgmann, Carl Mitcham, Bart Gremmen, Josette Jacobs, the Philosophy Group of Wageningen University, and two anonymous reviewers for their valuable comments on earlier drafts of this paper. I also thank the BioSolarCells research program for funding this project.

Open Access This article is distributed under the terms of the Creative Commons Attribution 4.0 International License (http://creativecommons.org/licenses/by/4.0/), which permits unrestricted use, distribution, and reproduction in any medium, provided you give appropriate credit to the original author(s) and the source, provide a link to the Creative Commons license, and indicate if changes were made.

\section{References}

Borgmann, A. (1987). Technology and the character of contemporary life: a philosophical inquiry. Chicago: University Of Chicago Press.

Borgmann, A. (1992). Crossing the postmodern divide. Chicago: University Of Chicago Press.

Borgmann, A. (2000). Reply to my critics. In E. Higgs, A. Light, \& D. Strong (Eds.), Technology and the Good Life? (1st ed., pp. 341-370). Chicago: University Of Chicago Press.

Borgmann, A. (2002). Response to my readers. Techné: Journal of the Society for Philosophy and Technology, $6(1), 76-85$.

Borgmann, A. (2006). Real American ethics: taking responsibility for our country (First ed.). Chicago: University Of Chicago Press.

Dupuy, J.-P. (2002). Energy and the mystery of iniquity. In L. Hoinacky \& C. Mitcham (Eds.), The challenges of Ivan Illich: A Collective Reflection (pp. 189-204). New York: State University of New York Press.

Gambrel, J. C., \& Cafaro, P. (2009). The virtue of simplicity. Journal of Agricultural and Environmental Ethics, 23(1-2), 85-108. doi:10.1007/s10806-009-9187-0.

Gehlen, A. (1980). Man in the age of technology. New York: Columbia University Press.

Gibson, J. (1977). The theory of affordances. In R. Shaw \& J. Bransford (Eds.), Perceiving, Acting, and Knowing (pp. 127-143). Hoboken, NJ: Wiley.

Hänggi, M. (2011). On the way to the 2000-watt society-Zurich's path to sustainble energy use (p. 32). Zurich: City of Zurich, Office for Environmental and Health Protection Zurich (UGZ). Retrieved from https:/www.stadt-zuerich.ch/2000-watt-society

Haworth, L. (2000). Focal things and focal practices. In E. Higgs, A. Light, \& D. Strong (Eds.), Technology and the Good Life? (1st ed., pp. 55-69). Chicago: University Of Chicago Press.

Higgs, E., Light, A., \& Strong, D. (Eds.). (2000). Technology and the good life? Chicago: University Of Chicago Press.

Ihde, D. (1990). Technology and the lifeworld: from garden to Earth (Indiana Series in the Philosophy of Technology). Indiana University Press.

Illich, I. (1973). Tools for conviviality. London: Marion Boyars Publishers.

Illich, I. (1974). Energy and equity. New York: Harper and Row.

Illich, I. (2013). The social construction of energy. In Beyond Economics and Ecology: The Radical Thought of Ivan Illich (pp. 105-123). London: Marion Boyars Publishers.

Jackson, T. (2011). Prosperity without Growth: Economics for a Finite Planet (reprint edition). In London. Washington DC: Routledge.

Latour, B. (1993). We have never been modern. (C. Porter, Trans.). Cambridge, Mass: Harvard University Press.

Mitcham, C. (1991). Tools for conviviality: argument, insight, influence. In P. T. Durbin (Ed.), Europe, America, and Technology: Philosophical Perspectives (pp. 17-56). Netherlands: Springer.

Mitcham, C., \& Rolston, J. S. (2013). Energy constraints. Science and Engineering Ethics, 19(2), 313-319. doi:10.1007/s11948-013-9446-3.

Plessner, H. (1975). Die Stufen des Organischen und der Mensch: Einleitung in die philosophische Anthropologie (3rd edition). Berlin: de Gruyter. 
Smil, V. (2007). Energy in nature and society: general energetics of complex systems (First ed.). Cambridge: The MIT Press.

Smil, V. (2010). Science, energy, ethics, and civilization. In M. L. Cohen, A. J. Leggett, W. D. Phillips, \& C. L. Harper (Eds.), Visions of discovery new light on physics, cosmology, and consciousness (pp. 709-729). Cambridge: Cambridge University Press.

Soper, K. (2008). Alternative hedonism, cultural theory and the role of aesthetic revisioning. Cultural Studies, $22(5), 567-587$.

Spence, E. (2012). Consumption and sustainability a neo-epicurean approach to a sustainable good life in a technological age. In P. Brey, A. Briggle, \& E. Spence (Eds.), The Good Life in a Technological Age (pp. 168-180). New York: Routledge.

Speth, J. G. (2009). The bridge at the edge of the world: capitalism, the environment, and crossing from crisis to sustainability. New Haven: Yale University Press.

Thaler, R., \& Sunstein, C. (2008). Nudge: improving decisions about health, wealth and happiness. Penguin.

Verbeek, P.-P. (2005). What things do: philosophical reflections on technology, agency, and design. University Park: Penn State University Press.

Verbeek, P.-P. (2011). Moralizing technology: understanding and designing the morality of things. Chicago: University Of Chicago Press. 